\title{
Two Prolonged Bee Visits Suffice to Maximize Drupelet Set for Red Raspberry
}

\author{
Corey J. Andrikopoulos ${ }^{1}$ \\ Department of Biology, Utah State University, Logan, UT 84322
}

\section{James H. Cane \\ USDA-ARS Pollinating-insect Research Unit, Utah State University, Logan, UT 84322}

Additional index words. honey bee, Apis mellifera, bumblebee, Bombus, pollination, stocking density, fruit yield

\begin{abstract}
Red raspberry is one of the many fruit crops reliant on the European honey bee for pollination services. Recent declines among managed honey bee colonies coupled with expanding U.S. acreage have led to a marked increase in the cost of U.S. colony rentals for raspberry. The current stocking density recommendation for raspberry is 2 to 5 colonies/ ha. This estimate is based on the assumption that a raspberry flower requires dozens of visits to achieve maximal drupelet set. Recent studies, however, suggest that far fewer visits are required for full drupelet set. Here, drupelet set resulting from bee visitation to a raspberry flower is assessed to determine if two prolonged visits will suffice to maximize drupelet set. For all three red raspberry cultivars examined there was no difference in drupelet set resulting from two visits when compared with openly pollinated flowers, the two visits being the first prolonged visit on each of two consecutive mornings. These findings should help refine honey bee stocking densities to better match the pollination needs of cultivated red raspberries.
\end{abstract}

Cultivated red raspberry (Rubus idaeus L.) is one of the numerous specialty crops dependent upon bees for fruit production (Klein et al., 2007). Although predominantly selffertile (Daubeny, 1971), raspberry flowers only partially self-pollinate due to insufficient contact between the anthers and the innermost stigmas within the flower (Free, 1993). Raspberry flowers contain 60 to 90 stamens arranged in an outer ring of whorls around a central receptacle, and a similar number of pistils arising spirally from the receptacle. Pistils must be individually pollinated; each ovary develops into a single-seeded drupelet when fertilized (Jennings, 1988). Cohesion of the aggregate fruit requires that a high percentage of drupelets set. Unmarketable berries result when too few drupelets develop, causing berries to be crumbly and misshapen, often with a terminal tuft of dried unpollinated pistils (Cane, 2005; Free, 1993; McGregor, 1976). Bee visitation is necessary to ensure adequate pollination of these innermost pistils.

Received for publication 6 Apr. 2018. Accepted for publication 13 July 2018.

This work was supported by the Integrated Crop Pollination project funded by the USDA National Institute of Food and Agriculture through award 2012-51181-20105 from the Specialty Crop Research Initiative.

We are grateful to Byron Love and Kristen Lambert for their assistance in data collection, and Diane Alston, Brent Black, and Chad Finn for reviewing earlier drafts of this manuscript.

${ }^{1}$ Corresponding author. E-mail: cja576@gmail. com.
Wild bees are often too scarce in larger raspberry fields to satisfy pollination needs (MacKenzie and Winston, 1984; Winston and Graf, 1982). Growers instead rely on rented colonies of European honey bees (Apis mellifera L.) as the primary pollinators of commercial raspberry in Europe and North America (Free, 1993). Honey bees are known to be effective pollinators of raspberry (Bekey, 1985; Cane, 2005, 2008; Chagnon et al., 1991; Sáez et al., 2014; Shanks, 1969; Willmer et al., 1994); however, there is disagreement as to the estimated number of visits required for full drupelet set. Bekey (1985) suggested that every flower may need as many as 68 honey bee visits, whereas other studies estimate around 5 to 10 visits to be sufficient (Chagnon et al., 1991; Sáez et al., 2014). More recent work examining the single-visit efficacy of honey bees for raspberry suggests that as few as two visits are sufficient to maximize yield (Andrikopoulos and Cane, 2018).

The longer a bee is in contact with a flower the more opportunity it has to contact and transfer pollen to stigmas. Drupelet set, therefore, increases with the cumulative duration of a bee's contact with a flower, up to about $150 \mathrm{~s}$ (Chagnon et al., 1991). The first visit to a virgin flower is far longer than the day's subsequent visits to the same flower (Bekey, 1985). This pattern accords with the daily cycle of nectar volume in a raspberry flower, which is usually greatest in the morning, having accumulated during the previous night (Bekey, 1985; Willmer et al., 1994). The first visitor of the day depletes the flower's nectar pool. Raspberry flowers remain receptive for at least two days, over which time they continually secrete nectar (Bekey, 1985; Eaton et al., 1968; Redalen, 1976; Willmer et al., 1994). As a consequence, this recharged nectar pool should elicit one prolonged bee visit on each of two days, during which foragers often straddle the receptacle and pivot about to drink nectar, thus ensuring contact with the central pistils. These two prolonged visits could be enough to maximize drupelet set.

An accurate estimate for the number of visits required for full fruit set is necessary to build more refined models of honey bee stocking density on farms. Bekey (1985) estimated that 2 to 5 colonies/ha are needed to pollinate raspberry. However, that calculation was based on the assumption of between 27 and 68 visits per flower for adequate pollination. If flowers only require two visits instead, the estimated honey bee stocking density for raspberry would be considerably less. This discrepancy has major economic implications for growers. Raspberries markets are expanding, evidenced by the doubling of land dedicated to cultivated raspberry between 1984 and 2014 (FAOSTAT, 2017). At the same time, faltering populations of managed honey bees have led to mounting hive rental prices. The price of colonies for raspberry has nearly doubled in Oregon and Washington over the past 20 years, now averaging \$40/colony (Burgett, 1997; USDA-NASS, 2016). In California, the rental price is even higher averaging \$92/ colony in 2016. Growers in California, Oregon, and Washington paid \$1.61 million for raspberry pollination in 2016 (USDA-NASS, 2016).

In this study, we compared drupelet set for four honey bee visitation treatments at three red raspberry cultivars: 1) unvisited flowers, 2) a single prolonged bee visit, 3) two prolonged bee visits, one on each of two consecutive days, and 4) openly visited raspberry flowers (open pollination). We posited that two prolonged honey bee visits to a single raspberry flower would be sufficient to achieve full drupelet set.

\section{Materials and Methods}

Experimental design. Studies were conducted in a small four-year-old planting at the USDA-ARS Pollinating Insect Research Unit in Logan, UT $\left(41^{\circ} 45^{\prime} 29.1^{\prime \prime} \mathrm{N} 111^{\circ} 48^{\prime} 44.5^{\prime \prime}\right.$ $\mathrm{W})$. The planting consisted of six $11 \mathrm{~m}$ rows with $3 \mathrm{~m}$ row spacing. Cultivars in the orchard were alternated by row to promote outcrossing, which is reported to have marked metaxenic effects for some cultivars (Colbert and de Oliveira, 1990; Żurawicz, 2016). Between 29 May and 2 June 2017, pollination by honey bees and occasional bumblebees was evaluated on the floricane crop for 'Cowichan' and 'Polka'. The mean air temperature for the observation period during this time ranged from 22.4 to $26.5^{\circ} \mathrm{C}$ (MesoWest, 2017). Pollination of 'Latham' was evaluated on 6 and 7 June 2017, when the 
mean air temperatures were $27.3{ }^{\circ} \mathrm{C}$ and $29.9{ }^{\circ} \mathrm{C}$ (MesoWest, 2017). Visits by honey bees and the few bumblebees (13 of 444 visits) were combined in this study, as previous work on 'Latham' and 'Cowichan' showed that these two bees are equally effective pollinators of these cultivars (Andrikopoulos and Cane, 2018). All observations were completed in fair weather, between 0900 and $1800 \mathrm{HR}$ MST.

We evaluated free-flying bees for pollination of red raspberry using controlled floral access. At the onset of flowering, we covered several hundred racemes with nylon mesh bags. Any open flowers were removed before bagging. As bloom progressed, we exposed three to four racemes each having $\geq 1$ open flower to foraging bees by removing the mesh bags. Flowers remained exposed for up to 10 min. We discarded any unvisited flowers, as well as the few flowers visited by species other than honey bees or bumblebees. Once a flower had been visited, we snipped one sepal (for identification), and replaced the bag with an attached numbered tag. The following day, half the flowers (149 out of 298) that had received single visits were randomly selected to receive a second visitation. As before, we removed three to four mesh bags sequentially for 10 min observation periods. If the focal flower was again visited, we snipped a second sepal, and the bag was once again replaced. Occasionally these racemes also bore virgin, one-day old flowers. If these flowers received a single visit before the second visit to the focal flower, a sepal was snipped and the flower was included in the one visit treatment, as were focal flowers that did not receive their second visit during the allotted exposure period. Overall, $90 \%$ of flowers (134 out of 149) selected for the two visit treatment received a visit during the second day's 10 min exposure period. We randomly selected fifty additional flowers per cultivar for the unvisited and open-pollinated treatments. Racemes containing flower buds designated unvisited remained enclosed in mesh bags until the flowers senesced. Tagged flowers designated as open-pollinated remained exposed for the entirety of the experiment. During flowering, we also measured the average durations of first visits at virgin and two-day old flowers for a subset of the focal flowers. Racemes remained bagged until fruit had set and drupelets were ready to be counted. To avoid loss due to pests, we picked berries while still green, but with sufficiently sized drupelets for counting. Only pollinated pistils will yield a swelling drupelet with a developing seed (Jennings, 1988).

Data analysis. For each cultivar, we compared the four pollination treatments for the numbers of drupelets per maturing raspberry using a mixed model one-way ANOVA (PROC MIXED; SAS Institute, 2006) (Littell et al., 1996). Plotted residuals of drupelet counts were judged to be normal for all three cultivars. Where relevant (failed Levene's test), we used a model for heterogeneous variance. We compared treatments for each cultivar by three a priori orthogonal contrasts between incrementally increasing numbers of visits received (0-1, 1-2, and 2-many visits).

\section{Results}

A total of 610 red raspberry flowers received pollination treatments (215 'Cowichan'; 224 'Latham'; 171 'Polka'). Each raceme contained 1.17 experimental flowers on average. Flowers visited by bees yielded raspberry fruits with far more drupelets than those of unvisited flowers (Figs. 1-3). Drupelet set varied with pollination treatment for all three cultivars $(\mathrm{F}=65-155, P<0.0001, \mathrm{n}=$ 173-215 fruits). For the three cultivars, fruits from unvisited flowers consistently had fewer drupelets than once-visited flowers $\left(\mathrm{F}_{[1,89-220]}=116-312, P<0.0001\right)$ (Figs. 1$3)$. Twice-visited flowers were equivalent to openly-visited flowers for drupelets per fruit $\left(\mathrm{F}_{[1,74-220]}=0.55-2.68, P=0.11-0.46\right)$. Only for 'Latham' were fruits of twice-visited flowers larger than once-visited flowers $\left(\mathrm{F}_{[1,220]}=5.7, P=0.017\right)$; drupelet counts were equivalent for flowers visited once or twice for 'Cowichan' $(P=0.08)$ and 'Polka' $(P=0.33)$ (Figs. 1-3). First honey bee visits of the day received by raspberry flowers were long, lasting about a minute per flower (Table 1). Thereafter, bees visited flowers much faster, working $5.2 \pm 2.1$ flowers per minute ( $\mathrm{n}=25$ bouts).

\section{Discussion}

For all three red raspberry cultivars tested in this experiment, bee visitation improved drupelet set 2-4 fold. Open pollinated flowers were amply visited by honey bees in our study, as evidenced by our brief $(<10 \mathrm{~m})$ waits for foragers to find unbagged flowers. Numbers of drupelets resulting from honey bees openly visiting 'Polka' flowers were comparable to the manually outcrossed flowers of 'Polka' reported by Żurawicz (2016) ( $\approx 85$ drupelets/flower). In our study, two first visits by a bee to a receptive flower on two successive days were sufficient to assure maximal drupelet set, comparable to open pollinated flowers. These first visits lasted about one minute on each of two successive mornings. For 'Cowichan' and 'Polka', even one prolonged visit yielded fruits with similar numbers of drupelets to those from openly visited flowers, suggesting that the dozens of additional visits to openly pollinated flowers are superfluous. This finding seems to sharply contrast with previous studies suggesting that from 5 to 68 visits are required to achieve maximum drupelet set (Bekey, 1985; Chagnon et al., 1991; Sáez et al., 2014).

Chagnon et al. (1991) reported the nearest estimate to our study findings, suggesting 5 to 6 visits or $\approx 150$ s of contact with the flower for sufficiency. The disparity between our estimates is likely due to visitation in their study occurring on single day. Visit duration is strongly correlated with the nectar volume

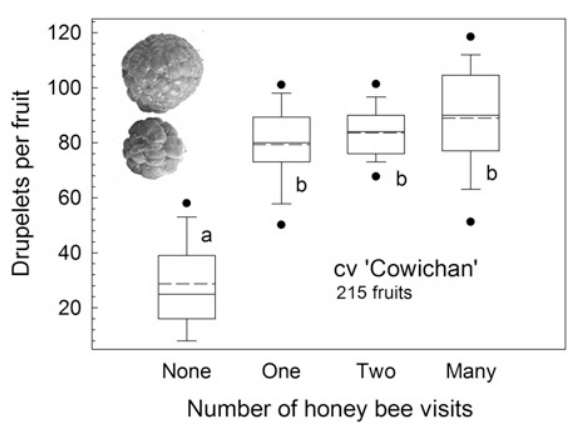

Fig. 1. Numbers of drupelets per fruit for 'Cowichan' resulting from no visitation $(n=50)$, one visit $(n=62)$, two visits $(n=53)$, and openly visited $(n=50)$ pollination treatments. The box plot depicts the median (solid cross-bar), mean (dashed cross-bar), 25th and 75th percentile (box), 10th and 90th percentile (stems), and outliers (dots). Letters denote means that are significantly different at $P \leq 0.05$.

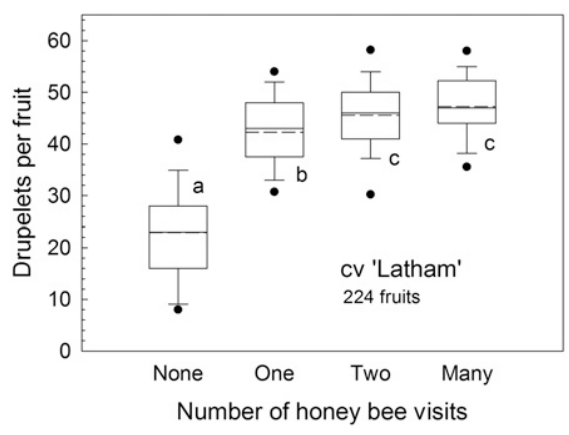

Fig. 2. Numbers of drupelets per fruit for 'Latham' resulting from no visitation $(\mathrm{n}=50)$, one visit $(n=73)$, two visit $(n=51)$, and openly visited $(\mathrm{n}=50)$ pollination treatments. The box plot depicts the median (solid cross-bar), mean (dashed cross-bar), 25th and 75th percentile (box), 10th and 90th percentile (stems), and outliers (dots). Letters denote means that are significantly different at $P \leq 0.05$.

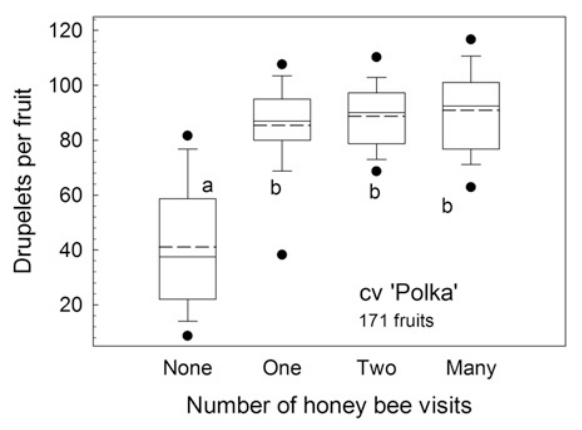

Fig. 3. Numbers of drupelets per fruit for 'Polka' resulting from no visitation $(n=50)$, one visit $(\mathrm{n}=41)$, two visit $(\mathrm{n}=30)$, and openly visited $(\mathrm{n}=50)$ pollination treatments. The box plot depicts the median (solid cross-bar), mean (dashed cross-bar), 25th and 75th percentile (box), 10th and 90th percentile (stems), and outliers (dots). Letters denote means that are significantly different at $P \leq 0.05$.

present in a flower (Bekey, 1985; Chagnon et al., 1991; Willmer et al., 1994). The duration of the first visit of the day to a receptive flower can average $>80 \mathrm{~s}$ (Bekey, 
Table 1. Mean $( \pm \mathrm{SE})$ and median of honey bee visit durations at virgin flowers on Day $1(n=62)$ and those same flowers visited once more on Day $2(\mathrm{n}=35)$. All raspberry cultivars are combined. Durations reported in seconds.

\begin{tabular}{lcc}
\hline & Mean \pm SE $(\mathrm{s})$ & Median \\
\hline First visit, day 1 & $58.7 \pm 3.3$ & 56 \\
First visit, day 2 & $67.7 \pm 6.7$ & 63 \\
\hline
\end{tabular}

1985) compared with an average duration of $<13 \mathrm{~s}$ for subsequent visits to the same flower (Bekey, 1985; Willmer et al., 1994). Raspberry flowers remain receptive for at least two days (Bekey, 1985; Eaton et al., 1968; Redalen, 1976; C.J. Andrikopulos, personal observation), and for some cultivars, including 'Latham' studied here, optimal drupelet set is achieved when pollination occurs over two or more days. This is presumably because stigmas within a flower do not all become receptive concurrently (Bekey, 1985; Eaton et al., 1968). Taking the difference in visit duration throughout the day into account, our estimate of two first visits over two days is in accord with the previous estimate of 5 to 6 visitations on a single day, as the cumulative duration of those two visits is likely to exceed the $150 \mathrm{~s}$ threshold. The average cumulative duration of the two visits for our study was $\approx 127 \mathrm{~s}$. Although this duration is slightly less than the $\approx 150 \mathrm{~s}$ previously estimated, the difference is likely attributable to variation in nectar secretion and receptivity among the cultivars used in the studies (Bekey, 1985; Willmer et al., 1994).

An accurate estimate of the number of bee visits required to maximize fruit yield is integral for estimating appropriate bee stocking densities for bee-dependent crops. The other variables needed for that calculation include bees' pollination efficacies, foraging tempos, their densities per unit area, floral density, and yield per acre. Current stocking density estimates for raspberry are 2 to 5 honey bee colonies/ha (Bekey, 1985; Free 1993). This estimate is based on each flower requiring dozens of bee visits to maximize fruit set; however, our results reveal that only two prolonged floral visits, one on each of two consecutive days, are required to achieve full drupelet set. This suggests that many farmers may be overstocking their fields with honey bee colonies, incurring additional rental costs without an offsetting gain in fruit yield. From a beekeeper's perspective, an orchard's volume of nectar could be collected by far fewer colonies. An overabundance of bee visitation has been shown to result in bees actually damaging raspberry stigmas, thus limiting drupelet set in over-visited flowers (Sáez et al., 2014). The results of our study should help to refine stocking density estimates for raspberry, potentially reducing growers' costs for hive rentals, while avoiding losses in fruit yield due to excessive bee visitation.

\section{Literature Cited}

Andrikopoulos, C.J and J.H. Cane. 2018. Comparative pollination efficacies of five bee species on raspberry. J. Econ. Entomol. (In press).

Bekey, R.S. 1985. Effects of method and timing of pollination and temperature on fruit development in red raspberry. PhD Diss. Oregon State Univ., Corvallis, OR.

Burgett, M. 1997. 1996 Pacific Northwest honey bee pollination survey. Oregon State Univ., Corvallis, OR.

Cane, J.H. 2005. Pollination potential of the bee Osmia aglaia for cultivated red raspberries and blackberries (Rubus: Rosaceae). HortScience 40:1705-1708.

Cane, J.H. 2008. An effective, manageable bee for pollination of Rubus bramble fruits, Osmia aglaia. Acta Hort. 777:459-464.

Chagnon, M., J. Gingras, and D. de Oliveira. 1991. Honey bee (Hymenoptera: Apidae) foraging behavior and raspberry pollination. J. Econ. Entomol. 84:457-460.

Colbert, S. and D. de Oliveira. 1990. Influence of pollen variety on raspberry (Rubus idaeus $\mathrm{L}$.) development. J. Hered. 81:434-437.

Daubeny, H.A. 1971. Self-fertility in red raspberry cultivars and selections. Amer. Soc. Hort. Sci. 96:588-591.

Eaton, G.W., H.A. Daubeny, and R.C. Norman. 1968. Pollination techniques for red raspberry breeding programs. Can. J. Plant Sci. 48:342344.

Food and Agriculture Organization of the United Nations. 2017. FAOSTAT database. FAO-ESS,
Rome, Italy. 12 Sept. 2017. <http://www.fao. org/faostat/en/\#data/QC>.

Free, J.B. 1993. Insect pollination of crops. 2nd ed. Academic Press, London, UK.

Jennings, D. 1988. Raspberries and blackberriestheir breeding, diseases and growth. Academic Press, London, UK.

Klein, A.M., B.E. Vaissière, J.H. Cane, I. Steffan-Dewenter, S.A. Cunningham, C. Kremen, and T. Tscharntke. 2007. Importance of pollinators in changing landscapes for world crops. Proc. Biol. Sci. 274(1608):303313.

Littell, R.C., G.A. Milliken, W.W. Stroup, and R.D. Wolfinger. 1996. SAS system for mixed models. SAS Inst. Inc., Cary, NC.

MacKenzie, K.E. and M.L. Winston. 1984. Diversity and abundance of native bee pollinators on berry crops and natural vegetation in the lower Fraser Valley, British Columbia. Can. Entomol. 116:965-974.

McGregor, S.E. 1976. Insect pollination of cultivated crop plants. Agricultural Handbook No. 496. USDA-ARS, Washington, DC.

Meso West. 2017. Meso West Data. Univ. of Utah, Salt Lake City, UT. 10 Oct. 2017. <http:// mesowest.utah.edu/>.

Redalen, G. 1976. Pollination and fruit set in raspberries. Acta Hort. 60:169-176.

Sáez, A., C.L. Morales, L.Y. Ramos, and M.A. Aizen. 2014. Extremely frequent bee visits increase pollen deposition but reduce drupelet set in raspberry. J. Appl. Ecol. 51(6):16031612.

SAS Institute. 2006. SAS/STAT User's Guide, version 9.1.3. SAS Institute, Cary, NC.

Shanks, C.H.J. 1969. Pollination of raspberries by honeybees. J. Apic. Res. 8:19-21.

U.S. Department of Agriculture - National Agricultural Statistics Service. July 2016. Noncitrus fruits and nuts 2015 summary. U.S. Dept. of Agric., Washington, DC.

Willmer, P.G., A.A.M. Bataw, and J.P. Hughes 1994. The superiority of bumblebee to honeybees as pollinators-insect visits to raspberry flowers. Ecol. Entomol. 19:271284.

Winston, M.L. and L.H. Graf. 1982. Native bee pollinators of berry crops in the Fraser Valley of British Columbia (Canada). J. Entomol. Soc. B.C. 79:14-20.

Żurawicz, E. 2016. Cross-pollination increases the number of drupelets in the fruits of red raspberry (Rubus idaeus L.). Acta Hort. 1133:145152. 